\title{
The Question of Residential Schools in Canada: Preserve, Demolish, or Repurpose?
}

\author{
Adriana Boffa \\ Department of Secondary Education \\ Faculty of Education \\ University of Alberta \\ boffa@,ualberta.ca
}

With public debates surrounding the removal of historical monuments in Canada (e.g., statues of, or schools named after, John A. Macdonald) and the United States (e.g., Confederate monuments), at times the voices of those who are most directly affected by their presence can be either drowned out or left out of the conversation entirely. It seems easy for the broader public to pass judgements and come to a consensus on a "right" way to approach such debates, but these judgements tend to be overly simplistic and removed from the immediate context and its attendant complexities. Those immersed in the situation face dynamics that are so complex that reaching consensus is difficult, as is this case with St. Mary's Indian Residential School on Kainai First Nation and St. Phillip's School on Keeseekoose First Nation. After these schools burned down, the communities were left with the residual mixed emotions at their loss, untimely or not (Smith, 2015; CBCNews, 2005).

Present and future communities can create new potentials for themselves in connection with the world and others around them, and the notion of place as well as physical structures in those places affect these potentialities. In this short essay, I am specifically considering what it means to undertake the Truth and Reconciliation Commission of Canada's (TRC) Call to Action \#79 (2015a) that calls "upon the federal government, in collaboration with Survivors, Aboriginal organizations, and the arts community, to develop a reconciliation framework for Canadian heritage and commemoration" (p. 9) in relation to the roughly 17 Indian Residential Schools (IRS) that are left of the original 140 (Parry, 2017). How can buildings hold power over a community's healing and the process of reconciliation? To what extent should the broader public have a say in a community's healing process? There is no single answer because this issue is fraught with complications.

We might begin to formulate responses from the Government of Canada's TRC (2015b) summary report detailing the injustices of "cultural genocide" (p. 55) committed upon the Indigenous peoples of this country, through their forced assimilation via the residential schooling system. According to this report, residential schools are responsible for the "loss of pride and selfrespect" of and for Indigenous peoples in Canada (p. VI). This "loss" and "cultural genocide," as can be surmised by engaging with this document, is firmly connected to a profound disconnect from place which consequently led to a disconnect from history, culture, language, and family.

\section{What is the answer? To repurpose? To demolish? To forget?}

Residential schools still left standing remain an imposing fixture (physically and emotionally) in various Indigenous communities. While some have been reclaimed and repurposed by the community (for use as Band offices or universities), others lay empty acting as ghostly reminders of a horrific past (Boffa, 2016; Parry, 2017). These structures are places of great trauma and unsettling memory. They are not merely buildings; rather, they are places that 
conjure temporal and spatial disturbances for all who are in their presence (Shields, 2013). The school buildings evoke memories, recall histories or pasts, generate physical and emotional effects, and transform the spaces around them (Boffa, 2016). Such a framing might indicate that these buildings ought to be demolished, as was the community decision for St. Michael's IRS in Alert Bay (Parry, 2017), but these schools can also be sites of reconciliation. IRS can be sites that elicit memories of trauma, but also sites of resilience and hope for better relations based upon witnessing past atrocities.

The words and phrases "witness," "witnessing," or to "bear witness" come up 85 times collectively throughout the TRC Executive Summary (2015b). In many of the testimonies, it asks for Canadians to "see [themselves] as witnesses" to the past and the stories presented in the document (p. 13). While one can witness by being mindful of one's expressed trauma (Riedel, 2014), there are ways of witnessing which require a much more nuanced attunement. Bracha Lictenberg Ettinger (2001), for instance, speaks of the notion of "wit(h)nessing" in an article entitled Wit(h)nessing Trauma and the Matrixial Gaze, where "wit(h)nessing" is conceptualized as being able to access the "non-cognitive" and that which "will always remain in many ways unsurmountable (sic), the constantly vanishing" (p. 107). Ettinger considers it as a kind of awareness that is not immediately tangible or understood, yet is very real-a "vibration"-like presence from the unconscious which can emerge into consciousness from an interaction with something that is produced from someone else or in connection with something else in the world we inhabit. This awareness is what occurs when one is engaging with aspects from one's unconscious that are affected emotionally (e.g., memories, traumas), and hence were triggered into action.

Although the TRC provides a national framework through the calls to action, each community can come up with their own path towards healing in regards to how they wish to address IRS as physical structures. Ry Moran, director of the National Centre for Truth and Reconciliation at the University of Manitoba, believes that these IRS sites: "are places that must be marked and acknowledged, even if they represent a dark and difficult chapter of this country's history" (Parry, 2017, para. 1). He strongly feels that there is a danger if "people continue to deny the harshness of these schools, the reality of these schools" and that "we are at risk of not remembering in the future... so we have to protect the evidence" (n.p.). But what, then, if the buildings' presence is too much of an emotional, physical, and financial burden to bear? Moran argues that if the community decides to remove the building, then those wishes should be respected; however, in their place he hopes that there is something to commemorate the location so that it is never forgotten or minimized (Parry, 2017).

\section{What are the implications for a future moving forward?}

The heart of the TRC (2015b) report is regarding reconciliation, not only for the survivors and their families, but for all Canadians. Reconciliation is about developing mutual respect, reciprocity, and a recognition that we are all interconnected in this process of healing which requires all of us learning from our shared and difficult past. Reconciliation is not just one thing we do to make ourselves feel better; it is something that needs to be adopted into our ethics of how we might engage with life differently (Boffa, 2016). Therefore, one needs to do more than just talk about reconciliation, "[one] must learn to practice reconciliation in our lives" (TRC, 2015b, p. 21). 
Part of this reconciliation is a realization that IRS are not just simple buildings that represent oppression; rather, they have a continual effect on those in the community as conduits to past, present, and future relations. Healing, therefore, might also begin with how we choose to engage with a given community, and respect their own unique path towards reconciling their trauma. As such, a response cannot be proposed from 'the outside' (e.g., public opinion, government policy, etc.); rather, it must emerge from the complex relations and situated knowledges of the community itself.

Connecting with the TRC report and IRS as artifacts of trauma and sites of learning allow us to consider the implications of how we might connect with the notion of reconciliation for which they call. The Online Etymology Dictionary (Harper, 2001-2017) sees place as a determined space, site, location, or "dimensional extent," the determined position of, as well as the action of having things "happen" (para. 1-4). Hence, the essence of place connotes an occupation by something or someone (or of an area); it connotes a definitive boundary that perhaps could be occupied. That said, can anyone ever really occupy place? Or, is occupy the word that should be used? What if space is seen differently, such as a framework that is "socially produced" (Shields, 2013, p. 8)? In this case, space becomes more than a physical space to occupy and it might become a place of relationality. In this way, a place might be rethought as a space that moves multi-directionally, and thus has no physical form or pre-given direction. It then becomes a place and space of potential collective becoming and healing.

The question of demolishing IRS or not is a complicated matter and there is a lot at stake. There is no single answer. The only certainty is that it is a process that is continually in progress. As stated in the TRC Report (2015b), "While the Commission has been a catalyst for deepening our national awareness of the meaning and potential of reconciliation, it will take many heads, hands, and hearts, working together, at all levels of society to maintain momentum in the years ahead" (p. 8). Although it is all too easy to become swept up in media controversy and to make sweeping generalizations about one "right" answer to the problems of troubling legacies, it is vital to reconciliation that we listen to the voices of those in the communities affected by these physical objects, and attend to the complexities inherent in the conversation.

\section{References}

Boffa, A. (2016, February 5). Re(building) to heal: La Loche, residential schools, reconciliation in Canada. Space \& Culture [website]. Retrieved from http://www.spaceandculture.com/2016/02/05/rebuilding-to-heal-la-loche-residentialschools-reconciliation-in-canada/

CBCNews. (2005, March 21). Residential school fire evokes mixed feelings: Former chief. CBCNews-Saskatchewan. Retrieved from http://www.cbc.ca/news/canada/saskatchewan/residential-school-fire-evokes-mixedfeelings-former-chief-1.523260

Ettinger, B. L. (2001). Wit(h)nessing trauma and the matrixial gaze: From phantasm to trauma, from phallic structure to matrixial sphere. Parallax, 7(4), 89-114.

http://doi.org/10.1080/13534640110089276

Harper, D. (2001-2017). Place (n.). Online etymology dictionary. Retrieved from http://www.etymonline.com/word/place 
Parry, T. (2017, September 26). Indigenous residential schools as sites of conscience, MPs urged. CBC News. Retrieved from http://www.cbc.ca/amp/1.4306944

Riedel, E. (2014). A depth-psychological approach to collective trauma in Eastern Congo. Psychological Perspectives, 57, 1-39.

Shields, R. (2013). Spatial questions: Cultural topologies and social spatialisations. London, United Kingdom: Sage.

Smith, A. D. (2015). Feelings mixed at loss of former residential school. Windspeaker, 22(10). http://www.ammsa.com/publications/alberta-sweetgrass/feelings-mixed-loss-formerresidential-school

Truth and Reconciliation Commission of Canada. (2015a). Truth and reconciliation commission of Canada: Calls to action. Retrieved from http://www.trc.ca/websites/trcinstitution/File/2015/Findings/Calls to Action English2.pdf

Truth and Reconciliation Commission of Canada. (2015b). Honouring the truth, reconciling for the future: summary of the final report of the Truth and Reconciliation Commission of Canada. Retrieved from http://epe.lac-

bac.gc.ca/100/201/301/weekly acquisition lists/2015/w15-24-FE.html/collections/collection 2015/trc/IR4-7-2015-eng.pdf 